\title{
Functionalization of Mesoporous Silica Materials Using Calix[4]arenes
}

\author{
MARIUS OLTEANU ${ }^{1,2}$, RALUCA SEPTELEAN ${ }^{3 *}$, OVIDIU NEMES ${ }^{4,1 *}$, DELIA GREC ${ }^{3}$, EMESE GAL ${ }^{3}$, DAN PORUMB ${ }^{3}$, GYORGY DEAK ${ }^{1}$, \\ ANDREEA BARAITARU ${ }^{1,2}$ \\ ${ }^{1}$ National Institute for Research and Development in Environmental Protection, 294 Splaiul Independenei, 060031, Bucharest, \\ Romania \\ 2Politehnica University of Bucharest, Faculty of Material Science and Engineering, 313 Splaiul Independentei, 060042, Bucharest, \\ Romania \\ ${ }^{3}$ Babes-Bolyai University, Faculty of Chemistry and Chemical Engineering 1 Mihail Kogalniceanu Str., 400084, Cluj Napoca, \\ Romania \\ ${ }^{4}$ Technical University of Cluj Napoca, Faculty of Materials and Environmental Engineering, 28 Memorandumului Str., 400114, Cluj \\ Napoca, Romania \\ Six new products were obtained by deposition of para-tert-butylcalix[4]arene (t-Bu-C4OH), calix[4]arene \\ $(\mathrm{C} 4 \mathrm{OH})$ and tetra-methoxy-calix[4]arene (C4OMe) on two types of SBA-15 mesoporous silica. All the \\ products were characterized through thermogravimetric methods and SEM microscopy. The obtained results \\ confirm the functionalization of the silica materials with the calixarene macrocycles. Considering all the \\ obtained products, the thermal analysis suggests the strongest connectivity to form between the C4OMe \\ systems and mesoporous silica substrate.
}

Keywords: functionalized calix[4]arene, mesoporous silica, thermal analysis, SEM microscopy

Calixarenes are organic macrocycles with 3-20 phenol rings obtained by the condensation of para-alkyl phenols and formaldehyde [1] which have been studied intensively due to their wide range of applications in the field of molecular recognition [2], chemical and electrochemical sensors [3], separation sciences [4], drug delivery [5] or catalysis [6].

The high versatility of calixarene compounds is based on the adjustability of the macrocycles cavity either by controlling the number of phenolic monomers or the functional groups grafted at the upper or lower rim of the system [7]. Functionalized calixarenes have proven their importance for the preparation of modified silica with multiple applications [8]. Due to the high versatility of the functional groups on the upper and lower rim of the calixarenes, these derivatives can be used as coupling agents in order to ensure a stronger connection at the interface between two materials. By conveniently choosing the $R$ and $R^{\prime}$ functional groups in upper or low er rim of the calixarene macrocycle, particular structural arrangements of the coupling agent scaffold are obtained. This leads to the fine tuning of the response towards various external perturbations (thermal, mechanical or radiations) of the newly designed material modified with such coupling agents.

We have been interested in the study of the calixarenes as coupling agents between different inorganic/inorganic, organic/organic or organic/inorganic substrates and we have already obtained some results concerning the deposition of functionalized calixarenes to inorganic substrates [9-13]. Functionalization of mesoporous silica materials using calix[4]arenes modified with the proper functional groups on the upper or lower rim of the macrocycles could increase their connectivity (by stronger interaction and multiple bonding points) to the inorganic substrate and therefore could afford promising coupling agents for the preparation of various materials. We focused our study on calix[4]arenes, mainly due to the preference of these compounds to stabilize in a cone conformer and thus allowing a better covering of the silica surface [9].
We present here the preparation, thermal behavior and SEM analysis of six new products obtained through the coupling of three derivatives of calix[4]arene (t-BuC4OMe, $\mathrm{C} 4 \mathrm{OH}, \mathrm{C} 4 \mathrm{OMe}$ ) onto two type of mesoporous silica materials (S1, S2).

\section{Experimental part \\ Materials and methods}

The ${ }^{1} \mathrm{H}$ NMR spectra were recorded on a Bruker Avance $400 \mathrm{MHz}$ spectrometer in $\mathrm{CDCl}_{3}$, with TMS as reference at a frequency of $400.13 \mathrm{MHz}$ and the IR spectra were recorded on a Bruker FTIR Vector 22, spectrometer, in $\mathrm{KBr}$.

The scanning electron microscopy experiments (SEM) were performed on a HITACHI SU-70 FE-SEM system coupled with an energy dispersive X-Ray spectrometer (EDS). For an adequate microstructural analysis, the nanopowders were mounted on metallic stabs through a double-sided adhesive carbon conductive tape and covered with an Ag metallic layer in order to ensure a good conductivity. The experiments were conducted using an acceleration voltage which ranged between $2-3 \mathrm{kV}$, a beam current of 28-30 nA and a working distance of $15 \mathrm{~mm}$.

Thermogravimetric and differential thermogravimetric analyses were performed on a STA 449 F5 J upiter thermal analysis system. All the experiments were carried out in an alumina crucible $(900 \mu \mathrm{L})$, with a heating rate of $10^{\circ} \mathrm{C} /$ $\mathrm{min}$. The temperature range in which the experiments were performed was from 25 to $800{ }^{\circ} \mathrm{C}$, with a final pitch of 1 minute. The measurements were achieved in a nitrogen atmosphere with a gas flow of $50 \mathrm{~mL} / \mathrm{min}$.

All the reagents were purchased from chemical suppliers (Merck, Sigma-Aldrich, Applichem, Acros Organics) and used without any further purification. Paratert-butylcalix[4]arene (further noted t-BuC4) was purchased from Acros Organics. All the other functionalized calix[4]arenes were prepared through procedures described in the literature $[14,15]$ and presented in figure 1 in results and discussions section.

The two types of SBA-15 mesoporous silica (identification codes $\mathbf{S 1}$ and $\mathbf{S 2}$ ) were obtained through

* email: sraluca@chem.ubbcluj.ro; ovidiu.nemes@sim.utcluj.ro 
methods which have been reported in the literature [16]. The general procedure for the preparation of the $\mathbf{S 1}$ and $\mathbf{S 2}$ mesoporous silica consists in the mixture of pluronic P123 in a diluted solution of hydrochloric acid with TEOS (tetraethyl ortho-silicate) at different temperatures [17]. The S1 mesoporous silica was obtained at a temperature of $35^{\circ} \mathrm{C}$, while the $\mathbf{S 2}$ mesoporous silica at a temperature of $40^{\circ} \mathrm{C}$ [16]. The preparation of the two types of mesoporous silica (S1 and S2) using our specific temperature conditions, lead to the formation of materials in cylindrical shapes, while other previously reported silica materials were obtained as spheres [17].

General procedure for the deposition of $\mathrm{BuC} \mathrm{BOH}, \mathrm{C} 4 \mathrm{OH}$ and C4OMe calixarenes on the S1 and S2 mesoporous silica.

A solution of calixarene $(0.3 \mathrm{~g})$ in ethanol $(7.5 \mathrm{~mL})$ was stirred for $60 \mathrm{~min}$ at $60^{\circ} \mathrm{C}$. The solution was poured over 0.5 $\mathrm{g}$ of mesoporous silica ( $\mathbf{S 1}$ or $\mathbf{S 2}$ type) and the resulting mixture was stirred for $24 \mathrm{~h}$ at $60^{\circ} \mathrm{C}$. The final product was obtained after filtration, rinsing with ethanol $(3 \times 5 \mathrm{~mL})$ and drying for $6 \mathrm{~h}$ at $100^{\circ} \mathrm{C}$.

The products thus obtained were characterized through specific physico-chemical methods such as TG, DTG, SEM.

\section{Results and discussions}

The main purpose of our study was to find the most suited method to bind the functionalized calixarenes like $\mathrm{t}-\mathrm{BuC} 4 \mathrm{OH}, \mathrm{C} 4 \mathrm{OH}$ and $\mathrm{C} 4 \mathrm{OMe}$ to an inorganic substrate (mesoporous silica, in this case) and to study the influence of the functional group connected to lower rim of the calixarene in terms of the strength of the bonding between the inorganic substrate and the organic macrocycle.

The used calixarenes were obtained following the pathway detailed in Figure 1.

All the prepared calix[4]arenes were separated from the reaction mixtures following the methods described by the corresponding literature data [14] and, to ensure the purity of the starting materials, they were all characterized by ${ }^{1} \mathrm{H}$ NMR, IR and melting points.

The ${ }^{1} \mathrm{H}$ NMR spectrum of the starting para-tert-butyl calix[4] arene (t-BuC4OH) underlines the cone conformation of the calixarene by the chemical shift of the signal corresponding to the protons of the bridging -
$\mathrm{CH}_{2}$ groups at 4.26 and $3.49 \mathrm{ppm}$ (for exo and endo protons). Furthermore, the deshielded resonance signal at $10.34 \mathrm{ppm}$, corresponds to the protons from the hydroxyl groups involved in the hydrogen bonds which are characteristic for a cone conformer.

The ${ }^{1} \mathrm{H}$ NMR spectrum of the calix[4]arene $(\mathbf{C 4 O H})$ shows, together with the disappearance of the signal corresponding to the tert-butyl group from $1.21 \mathrm{ppm}$ in the parent

$\mathrm{t}-\mathrm{BuC4OH}$, the appearance of a new signal in the aromatic region corresponding to the Hydrogen atom in the para- position of the phenyl ring. In the case of the methylated calix[4]arene $(\mathrm{C} 40 \mathrm{Me})$, the signal corresponding to the methyl group appears in the proton NMR spectrum at a chemical shift of $3.87 \mathrm{ppm}$. In all cases, all the characteristic signals for the protons of the calixarene systems appear at the expected chemical shifts $[1,7]$.

The IR spectra show the disappearance, in the methylated calixarene $\mathbf{C} 40 \mathrm{Me}$, of the broad band attributed to the hydroxyl group in the $\mathrm{t}-\mathrm{BuC4OH}$ and $\mathrm{C} 4 \mathrm{OH}$ from $3144 \mathrm{~cm}^{-1}$ and the appearance of a broad band at $1018 \mathrm{~cm}$. ${ }^{1}$ for the methoxy group in $\mathrm{C} 40 \mathrm{Me}$.

The calixarenes t-BuC4OH, C4OH and $\mathbf{C 4 O M e}$ were used in order to prepare new materials by their deposition on the $\mathbf{S 1}$ and $\mathbf{S 2}$ type of mesoporous silica, at room temperature in a solution of ethanol, at $60^{\circ} \mathrm{C}$, for 24 hours, according to a method developed in our group and previously used for the deposition of tetracarboxyl-paratertbutyl-calix[4]arene on short glass fibers [10] .

After the deposition of the t-BuC4OH, C4OH and $\mathrm{C} 40 \mathrm{Me}$ calixarenes systems on the $\mathbf{S} 1$ and $\mathbf{S} 2$ types of mesoporous silica, the six newly obtained materials having the codes specified in Table 1 were washed with ethanol several times and dried. The products were analyzed through thermogravimetric methods in order to assess the connection strength.

\section{Comparative TG and DTG analysis}

In order to evaluate the connection strength between the inorganic substrate and calixarene macrocycles, thermal analysis has been carried out and the thermogravimetric TG and DTG data are presented in Table 1.

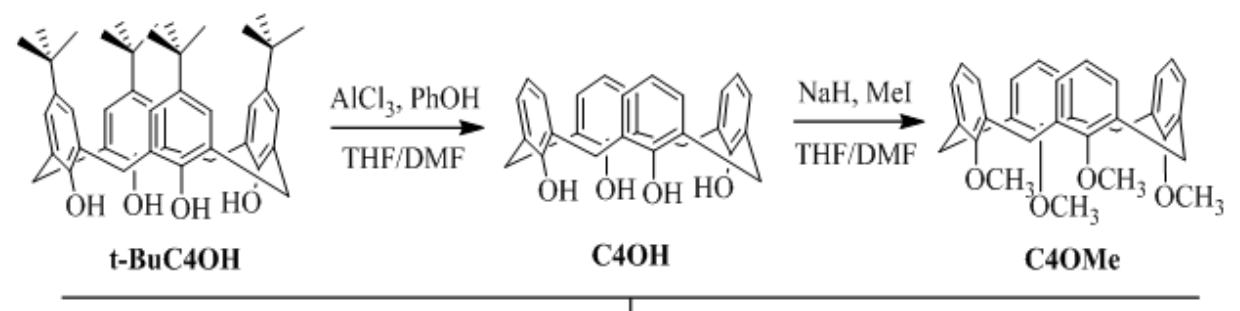

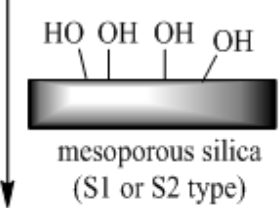

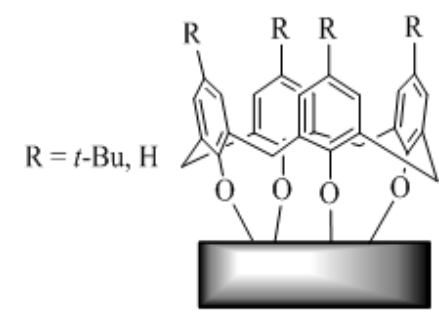

mesoporous silica functionalized with calixarene
Fig. 1. Synthesis pathway for the newly obtained mesoporous silica functionalized with calix[4]are derivatives 
Table 1

THERMOGRAVIMETRIC ANALYSIS DATA FOR THE NEW OBTAINED PRODUCTS

\begin{tabular}{|c|c|c|c|c|c|}
\hline \multirow[t]{2}{*}{ Product } & \multirow[t]{2}{*}{ Quantity } & \multicolumn{4}{|c|}{ Thermogravimetric (TG) and (DTG) analysis } \\
\hline & & $\begin{array}{c}\text { Total mass loss } \\
(\Delta \mathrm{mT})(\%)\end{array}$ & $\begin{array}{c}\text { Temperature range } \\
\left({ }^{\circ} \mathrm{C}\right)\end{array}$ & $\begin{array}{l}\text { Partial mass loss } \\
\left(\Delta \mathrm{m}_{\mathrm{p}}\right)(\%)\end{array}$ & $\begin{array}{l}\mathrm{T}_{\max } \\
\left({ }^{\circ} \mathrm{C}\right)\end{array}$ \\
\hline \multirow{3}{*}{ Sl_t$t$-BuC4OH } & \multirow{3}{*}{30.3} & \multirow{3}{*}{27.74} & $25-180$ & 4.51 & 78 \\
\hline & & & $180-500$ & 13.25 & 405 \\
\hline & & & $500-800$ & 9.98 & 520 \\
\hline \multirow{2}{*}{ Sl_C4OH } & \multirow{2}{*}{27.5} & \multirow{2}{*}{30.98} & $25-360$ & 8.64 & 80 \\
\hline & & & $360-800$ & 22.34 & 408 \\
\hline \multirow[t]{2}{*}{ Sl_C4OMe } & \multirow[t]{2}{*}{41.2} & \multirow[t]{2}{*}{26.24} & $25-300$ & 4.75 & 79 \\
\hline & & & $300-800$ & 21.49 & 397 \\
\hline \multirow[t]{2}{*}{$\mathrm{S} 2 \_t-\mathrm{BuC} 4 \mathrm{OH}$} & \multirow[t]{2}{*}{20.3} & \multirow{2}{*}{21.52} & $25-240$ & 9.08 & 78 \\
\hline & & & $240-800$ & 12.44 & 539 \\
\hline \multirow[t]{2}{*}{ S2_C4OH } & \multirow[t]{2}{*}{29.7} & \multirow[t]{2}{*}{24.41} & $25-360$ & 9.96 & $\overline{81}$ \\
\hline & & & $360-800$ & 14.45 & 407 \\
\hline \multirow[t]{2}{*}{ S2_C4OMe } & \multirow[t]{2}{*}{32.7} & \multirow[t]{2}{*}{31.72} & $25-280$ & 5.95 & $\overline{76}$ \\
\hline & & & $280-800$ & 24.77 & 396 \\
\hline S1 & $\overline{11.6}$ & 9.45 & $25-800$ & 9.45 & 69 \\
\hline$\overline{\mathrm{S} 2}$ & 19.7 & 13.56 & $25-800$ & 13.56 & 79 \\
\hline
\end{tabular}

The two starting mesoporous silica materials have an increased thermal stability until $800{ }^{\circ} \mathrm{C}$, having a single mass loss maximum $(9.45 \%$ for $\mathrm{S} 1$ and $13.56 \%$ in the case of S2), at $69^{\circ} \mathrm{C}$ and $79^{\circ} \mathrm{C}$ corresponding to the solvent loss (table 1) in the recorded DTG spectra. By comparison with the starting inorganic substrates (S1 and $\mathbf{S 2}$ ), the calixarene-silica materials show, in all cases, a mass loss higher than $20 \%$, proving the adsorption of the organic material onto the inorganic substrate.

For example, in the case of $\mathbf{S 1} \mathbf{t}-\mathbf{B u C 4 0 H}$ sample (obtained by the deposition of the para-tert-butylcalix[4] arene $\mathbf{t}-\mathbf{B u C 4 O H}$ on $\mathbf{S 1}$ substrate) the most important weight loss (13.25\%) is at $405^{\circ} \mathrm{C}$ and the second one $(9.98 \%)$ at $520^{\circ} \mathrm{C}$, which is in agreement with the thermal behaviour of the parent calixarene $\mathrm{t} \cdot \mathrm{BuC} \mathbf{C H}$, having the first decomposition stage (around $16 \%$ ) at $335^{\circ} \mathrm{C}$, associated with the 'detachement' of the tert-butyl groups from the upper rim of the calix[4]arene and the second one at $491^{\circ} \mathrm{C}$ (about $23 \%$ ) corelated with the destruction of the hydrophobic cavity [18, 19]. A similar behaviour is also noticed in the case of product S2 $\mathbf{t}-\mathbf{B u C 4 0 H}$ (see table 1) obtained by the deposition of the para-tertbutylcalix[4]arene $\mathbf{t} \cdot \mathbf{B u C 4 0 H}$ on substrate $\mathbf{S 2}$.

For the materials obtained by the deposition of the calix[4]arene without substituent group on upper rim, $\mathbf{C 4 O H}$ on the $\mathbf{S 1}$ and $\mathbf{S 2}$ mesoporous silica substrates (S1 $\mathbf{C 4 O H}$ and $\mathbf{S 2} \mathbf{C 4 O H}$ ), we can observe that these systems are stable to temperatures higher than $400^{\circ} \mathrm{C}$. The stability of these materials is due to the lack of a para-alkyl group on the upper rim of the used calix[4]arene. The major mass loss in the case of $\mathbf{S 1} \mathbf{C 4 O H}$ is observed at $408^{\circ} \mathrm{C}$ and for S2_ C4OH at $407^{\circ} \mathrm{C}^{-}$, while in the parent $\mathbf{C 4 O H}$ calixarene, the decomposition of organic macrocycle is recorded at $335^{\circ} \mathrm{C}$ [18]. In both cases, the decomposition temperature is slightly higher than in the case of the parent calixarene, as is also observed for other organic substances deposited on the inorganic material having a high adsorption capacity [20].

When the functionalization of $\mathbf{S 1}$ and $\mathbf{S 2}$ mesoporous silica materials is performed with the methoxy derivative of calix[4]arene ( $\mathbf{C 4 0} \mathrm{Me})$, the thermal analysis of the new S1_C4OMe and S2_C40 Me materials highlight the formation of new products as shown in Figure 2, but the temperature corresponding to the major mass loss is slightly lower in the two obtained materials when compared to the starting methoxy calix[4]arene macrocycle (C40Me).

This behavior suggests a relative strong connection of the organic macrocycle to inorganic substrates and due to this fact the $\mathrm{C}-\mathrm{O}$ bond is weakened, what leads to the faster thermal degradation of the $\mathbf{S 1} \mathbf{C 4 0} \mathbf{M e}$ and S2 C40 Me materials than the starting calix[4]arene ( C $\overline{40} \mathrm{Me})\left(396-397{ }^{\circ} \mathrm{C}\right.$ in the two obtained products compared with $409{ }^{\circ} \mathrm{C}$ in the starting calixarene). This agrees with some data reported in literature [21] which indicates that the thermal stability differs with the nature of the substituents and their placement in the system.

The thermogravimetric data recorded for the products obtained from the calixarene bearing $\mathrm{OH}$ groups at the lower rim implya physical interaction between the organic macrocycle and the inorganic material, while in the case of the methoxy-substituted calixarene the interaction appears to be stronger, suggesting a bonding of chemical nature. Similar behavior of the methoxy-derivatives for the functionalization of silica surfaces via formation of a strong connectivity between organic / inorganic substrates is evidenced in the field of siloxane derivatives [22].

\section{SEM Microscopy}

In order to additionally confirm the results obtained by thermogravimetric analysis for the products obtained by deposition of calixarene macrocycles on the mesoporous silica surface, SEM microscopy images were recorded on all new inorganic/organic materials, and are hereby presented in comparison with the SEM of the calixarene macrocycles and mesoporous silica (fig. 3).

SEM images recorded for $\mathbf{S} 1$ and $\mathbf{S} 2$ silica confirm the formation of this material in stick shape, due to the modifying of the working parameters when compared to the literature [17]. In the cases of S1 and S2 silica, the 


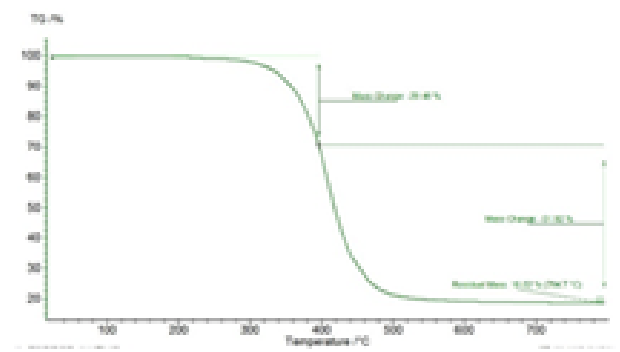

C4OMe (TG plot)

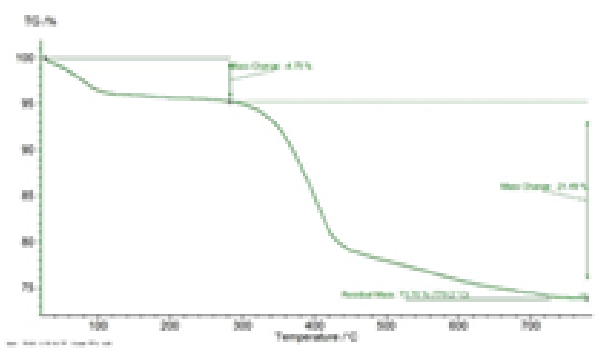

S1_C4OMe (TG plot)

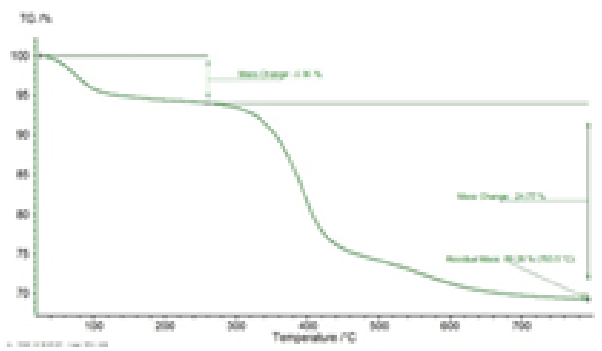

S2_C4OMe (TG plot)

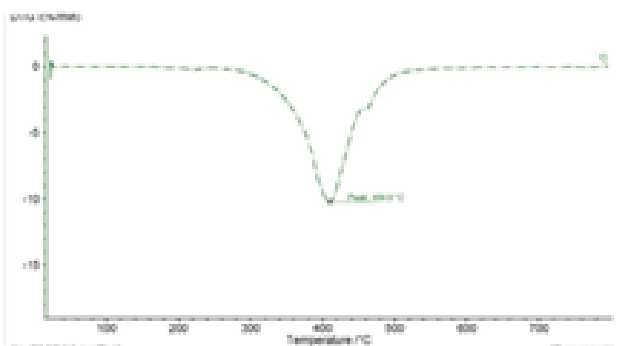

C4OMe (DTG plot)

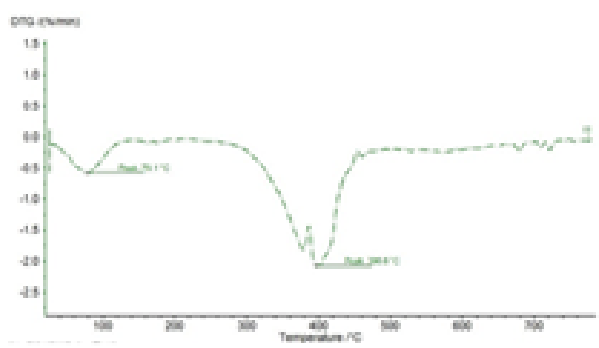

S1_C4OMe (DTG plot)

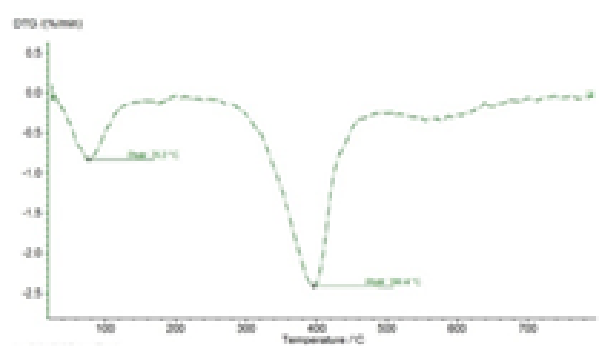

S2_C4OMe (DTG plot)

Fig. 2. Thermal behavior of the newly obtained S1_C40 Me and S2_C40 Me products and the start methoxy derivative calix[4]arene C40Me

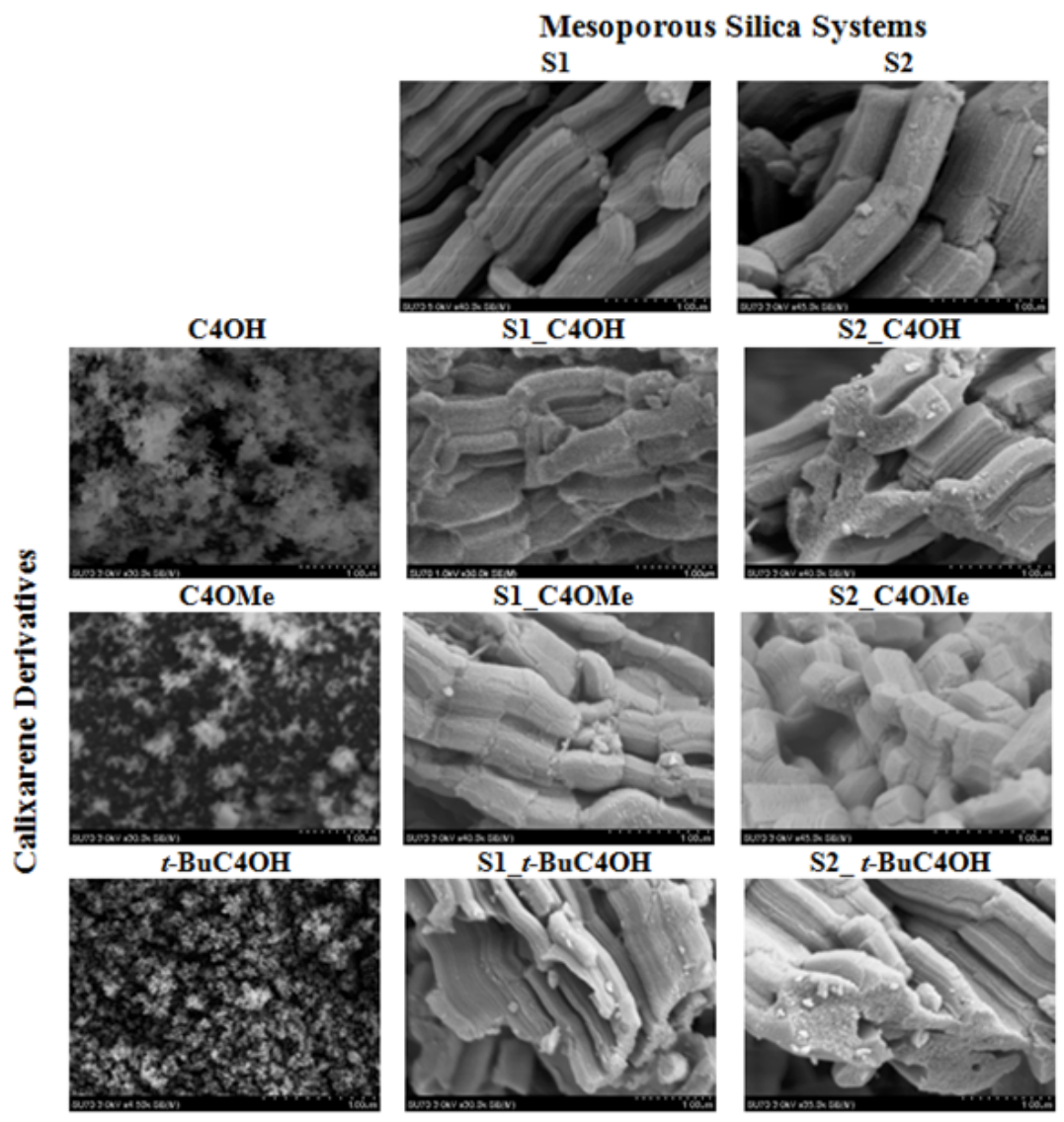

Fig. 3. SEM images for the newly obtained product by deposition of calix[4]arenes on the mesoporous silica system $\mathbf{S 1}$ and $\mathbf{S 2}$ compared with the SEM images for the started organic and inorganic materials 
existence of fine crevasses is visible along the inorganic sticks, whereas in the case of samples obtained by depositing the calixarenes on silica, they disappear; being probably filled with the organic compound (see figure 3).

SEM images also show a uniform deposition of organic macrocycles on the inorganic substrate with a predominance in the case of $\mathbf{S 1} \mathbf{C} 40 \mathrm{Me}$ and $\mathbf{S 2} \mathbf{C 4 0 M e}$ respectively, which is in agreement with the thermogravimetric results.

\section{Conclusions}

Para-tert-butylcalix[4]arene (t-Bu-C4OH), calix[4]arene $(\mathrm{C} 4 \mathrm{OH})$ and tetra-methoxy-calix[4]arene (C4OMe) were used in order to functionalize two different types of SBA-15 mesoporous silica (S1 and S2). This lead to the preparation of six new materials which have been characterized through physical-chemical methods. The TGA analysis of the prepared materials show that in all the cases, the calixarene macrocyles bonded on the inorganic substrates. Furthermore, the TGA analysis suggests that the C4OMe functionalized organic macrocyle exhibits a strong connection to the silica material. These results are confirmed by SEM microscopy study that suggests the deposition of the calixarene onto the surface of the studied silica materials.

Acknowledgment: This work was supported by Babes-Bolyai University, Faculty of Chemistry and Chemical Engineering and Institute of Research, Development, Innovation in Applied Natural Sciences. A part of the presented data was achieved through a project supported by a grant of the Romanian Ministry of Research and Innovation, within the Research Programme NUCLEU -MARES -PN 18 260104.

\section{References}

1.GUTSCHE, C.D., Calixarene Revisited, The Royal Society of Chemistry, Thomas Graham House, Cambridge, UK, 1998.

2.IKEDA, A., SHINKAl, S., Chem. Rev., 97(5), 1997, p. 1713.

3.SONG, M., SUN, Z., HAN, C., TIAN, D., LI, H., KIM, J. S., Chem. - Asian J., 9, 2014, p. 2344.

4.MOKHTARI, B., POURABDOLLAH, K., DALALI, N., J. Incl. Phenom. Macrocycl. Chem., 69, 2011, p. 1.
5.SANSONE, F., BALDINI, L., CASNATI, A., UNGARO, R., Supramol. Chem., 20, 2008, p. 161.

6.CACCIAPAGLIA, R., DI STEFANO, S., MANDOLINI, L., SALVIO, R., Supramol. Chem., 25, 2013, p. 537.

7.GUTSCHE, C.D., Calixarene: An Introduction, (Monographs in Supramolecular Chemistry), ed. STODDARD, J. F., The Royal Society of Chemistry, Thomas Graham House, Cambridge, UK, 2008.

8.ESPINAS, J., PELLETIER, J., SZETO, K. C., MERLE, N., LE ROU, E., LUCAS C., DE MALLMAN, A., BASSET J. -M., TAOUFIK M., THIVOLLECAZAT, J., Micropor. Mesopor. Mat., 188, 2014, p. 77.

9.RANETE, R., PETRAR, P. M., SEPTELEAN, R., PERHAITA, I., NEMES, G., Studia UBB Chemia, 60, 2, 2015, p. 15.

10.SEPTELEAN, R. A., VELNAZAROV, M., PRODAN, D., PERHAITA, I., NEMES, O., MOLDOVAN, M., Studia UBB Chemia, 62, 4, 2017, p. 381. 11.BIBIRE, N., VIERIU, M., TANTARU, G., APOSTU, M., AGOROAEI, L., PANAINTE, A.D., ZNAGOVAN, A, VLASE, A., Rev. Chim (Bucharest), 65, no. 7, 2014, p. 807.

12.APOSTU, M., TANTARU, G., VIERIU, M., PANAINTE, A.D., BIBIRE, N., AGOROAEI, L., Rev. Chim (Bucharest), 68, no. 4, 2017, p. 683.

13.TANTARU, G., APOSTU, M., Rev. Chim (Bucharest), 61, no. 7, 2010, p. 632.

14.GUTSCHE, C. D. LEE-GIN, L., Tetrahedron, 42, 6, 1986, p. 1633.

15.GUTSCHE, C. D., DHAWAN, B., LEVINE, J. A., NO, K. H, BAUER, L. J., Tetrahedron, 39, 3, 1983, p. 409.

16.OLTEANU, M., BARAITARU, A., DUMITRU, D., MONCEA, A., DEAK, G., BUTNARIU, C., PREDESCU, C., UPB Scientific Bulletin, Series B, Chemistry and Materials Science, ISSN 145-2331, 2019, accepted for publication.

17.KATIYAR, A., YADAV, S., SMIRNIOTIS, P. G., PINTO, N. G., J. Chromatography A, 1122, 1-2, 2006, p. 13.

18.DELIGOZ, H., OZEN, O., CILGI, G. K., CETISLI, H., Thermochim. Acta, 426, 2005, p. 33.

19.SAPONAR, A., POPOVICI, E. -J ., PERHAITA, I., NEMES, G., CADIS, A. -I., J. Therm. Anal. Calorim., 110, 2012, p. 349.

20.NAYAB, S., BAING, H., GHAFFAR, A., TUNICEL, E., OLUZ, Z., DURAN, H., YAMEEN, B., RSC Adv., 8, 2018, p. 23963.

21.ELCIN, S., KOYUNDERELI, G., DELIGOZ, C. H., Polycyclic Arom. Comp., 37, 2017, p. 46.

22.GUNJI, T., KABURAGI, H., TSUKADA, S., ABE, Y., J. Sol-Gel Sci. Technol., 75, 2015, p. 564.

$\overline{\text { Manuscript received: } 15.06 .2019}$ 